УДК 902.94

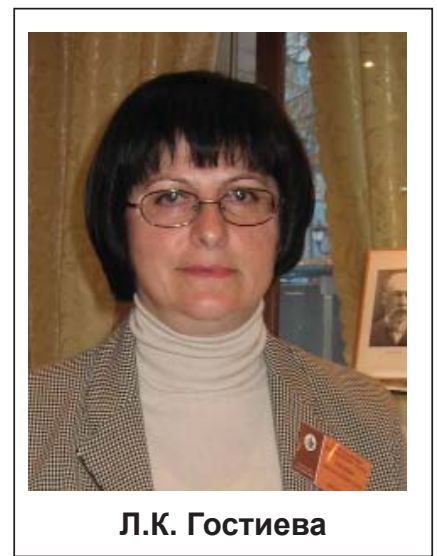

Лариса Казбековна Гостиева

Северо-Осетинский институт гуманитарных и социальных исследований им. В.И. Абаева - филиал Владикавказского научного центра Российской академии наук, доцент, старший научный сотрудник отдела этнологии, кандидат исторических наук, Владикавказ, e-mail: agost@mail.ru

\title{
Вклад Б.А. Калоева в развитие этнографического кавказоведения
}

\begin{abstract}
Аннотация. В статье рассмотрен вклад Б.А. Калоева в развитие этнограсического кавказоведения. Проанализированы работы ученого по этнографии чеченцев, ингушей, балкарцев, агулов, лезгин и др. Выявлено главное направление его научных интересов: разработка одной из сфер культуры жизнеобеспечения народов Северного Кавказа - хозяйства. Акцентировано внимание на значимости показа ученым многообразия хозяйственной сферы бытовой культуры северокавказских народов и ее изменения в XX в. Сделан вывод о значительном научном вкладе Б.А. Калоева в развитие этнографической науки Кавказа.

Ключевые слова: Б.А. Калоев, этнография, кавказоведческие исследования, земледелие, скотоводство, этнокультурные связи.
\end{abstract}

Larisa K. Gostieva

V.I. Abaev North Ossetian Institute for Humanitarian and Social Studies, Senior researcher of the Department of Ethnology, PhD, associate Professor, Senior researcher of the Department of Ethnology, Vladikavkaz, e-mail: lagost@mail.ru

\section{B.A. Kaloev's contribution to the development of ethnographic Caucasian studies}

\begin{abstract}
The article considers the contribution of B.A. Kaloev in the development of ethnographic Caucasian studies. The works of the scientist on the ethnography of Chechens, Ingush, Balkars, Aguls, Lezgins and others are analyzed. The main direction of his scientific interests is revealed: the development of one of the spheres of the culture of life support of the peoples of the North Caucasus - the economy. Attention is focused on the importance of showing scientists the diversity of the economic sphere of everyday culture of the North Caucasian peoples and its changes in the twentieth century. The conclusion is made about the significant scientific contribution of B.A. Kaloev in the development of the ethnographic science of the Caucasus.
\end{abstract}

Keywords: B.A. Kaloev, ethnography, Caucasian studies, agriculture, cattle breeding, ethnocultural ties.

15 февраля 2021 г. исполнилось 105 лет со дня рождения известного кавказоведа, доктора исторических наук, заслуженного деятеля науки РСО-А Бориса Александровича Калоева (1916-2006) - автора крупных монографий и многочисленных статей по вопросам этнологии Осетии и Кавказа. С течением времени влияние ученого на развитие осетиноведения и кавказоведения не ослабело. Так, фрундаментальный труд Б.А. Калоева «Осетины. Историко-этнографическое исследование» [1], выдержавший три издания, и сейчас остается одним из наиболее часто цитируемых в современных этнологических осетиноведческих и кавказоведческих исследованиях.

Научная деятельность Б.А. Калоева началась в 1948 г., когда он поступил в аспирантуру Института этнографии АН СССР. Его научным руководителем сначала стал крупный ученый-кавказовед Г.А. Кокиев, подвергнувшийся в 1949 г. жестокой репрессии (умер в заключении в 1955 г., посмертно реабилитирован), а потом - М.О. Косвен, ученый с мировым именем, один из корифеев отечественной этнографической науки. М.О. Косвен имел большое влияние на формирование научных интересов молодо- го кавказоведа. Воздействие на научные взгляды Б.А. Калоева оказали и другие крупные ученые, стоявшие у истоков российской этнографической и антропологической науки: В.В. Бунак, Е.М. Шиллинг, С.П. Толстов, С.А. Токарев, П.И. Кушнер, М.Г. Левин, Н.Ф. Дебец, Н.Н. Чебоксаров. Многие из них занимались кавказоведческой тематикой.

В 1951 г. Б.А. Калоев стал сотрудником сектора народов Кавказа московской части Института этнографии АН СССР, одного из основных центров отечественного кавказоведения. В том же году он блестяще защитил кандидатскую диссертацию по моздокским осетинам [2].

Б.А. Калоев принял активное участие во всех крупных кавказоведческих разработках сектора: написании тома «Народы Кавказа» из многотомной серии «Народы мира. Этнографические очерки» и коллективного труда «Очерки общей этнограффии. Азиатская часть СССР», исследовании процессов национальной консолидации у народов Дагестана, составлении Кавказского историкоэтнографического атласа, изучении современных этнических процессов и т. д.

Первые кавказоведческие исследования Б.А. 
Калоева в 1950-1960 гг. проходили в рамках подготовки сектором народов Кавказа фундаментального двухтомного издания «Народы Кавказа» из серии «Народы мира. Этнографические очерки» [3]. Этот масштабный этнографический труд, в котором представлены монографические очерки о 23 этносах Кавказа, ознаменовал важный этап в развитии отечественного кавказоведения и до сих пор сохраняет свое значение как справочноэнциклопедическое издание. В первый том «Народов Кавказа», в котором были представлены народы Северного Кавказа, вошли четыре очерка, написанные Б.А. Калоевым [4]. Он также принял участие в подборе иллюстраций и составлении указателей для издания.

При участии Б.А. Калоева написан также большой раздел «Народы Кавказа» в коллективном труде Института этнографрии «Очерки общей этнографии. Азиатская часть СССР» [5].

С 1957 г., сразу после восстановления национальной государственности чеченцев и ингушей, Б.А. Калоев в течение ряда лет вел среди них интенсивную этнографическую работу, побывал почти во всех больших селах горной и равнинной Чечено-Ингушетии. Свои экспедиционные поездки к чеченцам и ингушам он подробно описал в книге «Записки кавказоведа» (глава «Вайнахи») [6].

Две статьи, посвященные русско-вайнахским экономическим и культурным связям, вышли в журнале «Советская этнография» [7; 8]. По мнению ученого, русско-вайнахские связи сыграли исключительно важную роль в жизни чеченцев и ингушей. В 1960 г. Б.А. Калоев опубликовал монографические очерки «Чеченцы» [9] и «Ингуши» в первом томе «Народов Кавказа» [10].

Для написания очерков об агулах и лезгинах Дагестана Б.А. Калоев вошел в состав специально созданной в секторе Южно-Дагестанской экспедиции. Летом 1952 г. он совершил свою первую поездку к агулам, одному из малочисленных и неизученных в то время народов лезгинской группы Дагестана. Полевые исследования Б.А. Калоева проходили в рамках комплексного изучения процессов национальной консолидации у народов Дагестана [11, с. 33].

Не имея предшественников в изучении истории и этнографии агулов, Б.А. Калоев сосредоточил свои усилия на выявлении особенностей материальной и духовной культуры, языковых и культурных аспектов этнических процессов, нового и традиционного в культуре. Результаты экспедиционных поездок к агулам в 1952-1953 гг. легли в основу нескольких публикаций. Две небольшие работы по истории земельных отношений, поселению и жилищу агулов вскоре вышли в «Кратких сообщениях Института этнографиии» $[12 ; 13]$.

В 1955 г. под редакцией М.О. Косвена вышел в свет коллективный сборник «Народы Дагестана», подготовленный московскими и дагестанскими кавказоведами. В размещенном в сборнике очерке Б.А. Калоева об агулах большое место было уделено изучению современного быта агулов [14]. В 1960 г. монографический очерк Б.А. Калоева «Агулы» был опубликован в первом томе «Народов Кавказа» [15, с. 529-536].

В 1962 г. в «Кавказском этнографическом сборнике» была опубликована обстоятельная статья Б.А. Калоева «Агулы (историкоэтнографический очерк)», в которой исследована как традиционная бытовая культура агулов, так и их современная культура [16, с. 69-109]. Повсеместное распространение у агулов, по наблюдению автора, получило агуло-лезгино-русское многоязычие.

Почти четыре года (1954-1957) Б.А. Калоев посвятил изучению лезгин, одного из крупных и интереснейших народов Дагестана. К сожалению, работы Б.А. Калоева о лезгинах (7 а. л.) и агулах (4 а. л.), подготовленные для коллективного сборника «Народы южного Дагестана», по независящим от молодого ученого причинам, остались неопубликованными. Однако материалы Б.А. Калоева о лезгинах были использованы в очерке «Лезгины» в первом томе «Народов Кавказа» [4, с. 503-519]. Борис Александрович изучал и другие народы Дагестана. Чаще всего ему приходилось бывать у аварцев и лакцев, предки которых в средние века соседствовали с аланами. Экспедиционные поездки ученого в Дагестан нашли свое отражение в его книге «Записки кавказоведа» (глава «Народы Дагестана») [6, c. 196-272]

В начале 60-х гг. Б.А. Калоев принял участие в крупном исследовании, посвященном изучению культуры и быта аула Шонгеновский Адыгейской автономной области. Для коллективной монографии «Культура и быт колхозного крестьянства Адыгейской автономной области», посвященной всем сорерам жизни населения аула, он написал раздел о хозяйстве колхоза и производственном быте колхозников [17, с. 59-82]. 
Б.А. Калоев являлся одним из авторов двух глав - «Культура народов Северного Кавказа в XVI-XVIII вв.» и «Культура народов Северного Кавказа в дореволюционный период (до 1861 г.)» - в двухтомном коллективном труде «История народов Северного Кавказа с древнейших времен до конца XX в.» [18].

Главным направлением научных интересов Б.А. Калоева в этнографическом кавказоведении стала разработка одной из сфер культуры жизнеобеспечения народов Северного Кавказа - хозяйства. Выбор этой проблематики во многом определялся тем, что в 1960-е гг. в связи с работой над Кавказским историческо-этнографическим атласом (КИЭА) оживились исследования всех сфер культуры жизнеобеспечения (хозяйство, поселения, жилище, одежда, пища, транспорт). Всю работу в регионе по составлению КИЭА возглавлял сектор народов Кавказа, сотрудником которого был Б.А. Калоев.

Ученый разработал для КИЭА два раздела «Земледелие» и «Скотоводство». В 1968 г. им была составлена и опубликована «Программа сбора материалов по земледелию и скотоводству для Кавказского историко-этнографического атласа» [19].

На трудоемкую работу по составлению КИЭА Б.А. Калоев затратил много сил и времени. Ученый изучил традиционное хозяйство девяти горских народов Северного Кавказа. При этом он старался охватить полевыми исследованиями наиболее крупные районы проживания каждого народа. Возглавив в 1970 г. Северо-Кавказский отряд комплексной экспедиции Института этнографии АН ССР по сбору полевого материала для КИЭА в Ингушетии и Чечне, Б.А. Калоев провел этнографические изыскания в горной и равнинной Ингушетии. Затем экспедиция переехала в Чечню, где ученым были обследованы наиболее крупные горные и равнинные села.

Изучение народов Северного Кавказа не ограничивалось лишь указанными разделами атласа, а велось комплексно с охватом всех областей их этнографии. Отсутствие финансирования и соответствующей типографской базы для издания карт, к сожалению, не позволили Институту этнографии издать столь важный для развития науки КИЭА. Материалы КИЭА были опубликованы в виде многочисленных книг и статей.

Б.А. Калоев издал в рамках КИЭА статьи [20, с. 43-53; 21] и две капитальные монографии «Земледелие народов Северного Кавказа» [22] и «Скотоводство народов Северного Кавказа (с древнейших времен до начала XX века)» [23], в которых на обширных полевых этнографических материалах, архивных и музейных источниках, данных археологии исследовал традиционную систему и этнические особенности земледельческой и скотоводческой культуры коренного населения Северного Кавказа. Ученому удалось решить в этих книгах такие важные теоретические проблемы, как углубление разработки вопросов классификации и типологии элементов хозяйства и выработки принципов их картографирования.

Примененный в книге «Земледелие народов Северного Кавказа» метод картографирования позволил автору проследить на протяжении второй половины XIX - начала XX в. распространение по трем вертикальным зонам региона (высокогорной, горной, равнинной) традиционных культурных растений и земледельческих орудий, новых культур, сельскохозяйственных машин.

В книге освещены этапы развития производящего хозяйства народов Северного Кавказа, системы земледелия, сельскохозяйственные орудия, земледельческие культуры, хозяйственные постройки, традиционные верования и обряды, связанные с сельскохозяйственным календарем. Автор восстановил описание некоторых исчезнувших традиционных земледельческих орудий, процессов земледелия, состава культурных растений. Книга содержит большой картографический материал.

В монографии «Скотоводство народов Северного Кавказа (с древнейших времен до начала XX века)» Б.А. Калоев рассмотрел породы скота, формы его содержания, приемы выращивания молодняка, условия труда скотоводов, верования, связанные со скотоводством. Автору удалось описать традиционные формы скотоводства (многие из которых давно исчезли), видовой состав стада у населения Предкавказья различных эпох и регионов. Монография содержит большой иллюстративный и картографический материал, терминологические таблицы.

В 1994 г. в выпуске материалов по теме «Народы Кавказа» к серии «Народы и культуры», подготовленном отделом народов Кавказа Института этнологии и антропологии РАН, Б.А. Калоев опубликовал раздел о специфике земледелия народов Северного Кавказа и Дагестана [24, с. 155-199].

Указанные монографии Б.А. Калоева, основанные на богатом полевом материале, позволили представить все многообразие хозяйственной сферы бытовой культуры народов Северного Кавказа и проследить ее изменения в XX в.

В 80-е годы XX в. Б.А. Калоев исследовал проблемы этнокультурных контактов народов Сeверного Кавказа. Он опубликовал две работы по этнокультурным контактам осетин и вайнахов. В небольшой статье Б.А. Калоев проанализировал народные предания как источник по происхождению некоторых осетино-вайнахских фрамилий [25]. В серийном тематическом издании «Кавказский этнографический сборник» Б.А. Калоев выступил со статьей «Осетино-вайнахские этнокультурные связи» [26]. Основа этих контактов, по мнению исследователя, была заложена в эпоху появления на Кавказе алан. О развитии этнокультурных связей в период средневековья свидетельствовали археологические данные об аланских захоронениях. Автор выявил много сходных черт в хозяйстве, 
общественном и семейном быту, традиционных верованиях осетин и вайнахов. Интенсивные культурные контакты, по его мнению, отражены и в языках: в осетинском и ингушском языках свыше 200 лексических схождений.

В 1972 г. Б.А. Калоев опубликовал статью «Oceтинско-балкарские этнографические параллели», основой которой, наряду с архивными источниками, стали сведения, собранные автором в 1966 г. во время экспедиции в Балкарию и Карачай [27].

Осетино-балкарские этнографические связи, по мнению Б.А. Калоева, охватывали длительный хронологический период и восходили к первым контактам алан с тюркскими народами. Множество точек соприкосновения ученый нашел в земледелии и скотоводстве соседних народов, особенно в хозяйственном быте скотовода, в годовом цикле ухода и содержания скота. Он предположил, что распространенная до начала XX в. в Осетии «карачаевская» порода овец составляла разновидность осетинской овцы. В современной скотоводческой практике балкарцев наряду с тюркскими числительными применялся осетинский парный счет, по старой иранской десятичной системе. Подобный счет парами известен и в Карачае.

Б.А. Калоев привел большое количество осетинских топонимических названий, сохранившихся до настоящего времени в Балкарии и Карачае. Он сообщил о сходных фамилиях, появившихся в течение нескольких столетий у балкарцев, карачаевцев и осетин, отметил такой активно действующий канал культурного обмена, как смешанные браки. Б.А. Калоев обнаружил идентичные ритуалы в структуре семейно-бытовой обрядности указанных народов, нашел много общего в домусульманских воззрениях балкарцев и карачаевцев и осетинских верованиях (например, охотничье божество Апсаты- осет. Афсати).

Основу трудов этнографа-полевика Б.А. Калоева составили этнографические материалы, собранные в научных экспедициях, охвативших почти весь Северный Кавказ. В изучении некоторых народов он явился первопроходцем. Ценные оригинальные сведения, полученные порой в труднодоступных районах кавказского высокогорья, позволили ему проследить за изменениями этнографической действительности на Северном Кавказе, начиная с 50-х годов XX в.

Научное достоинство полевых изысканий Б.А. Калоева, проведенных во время кавказских поездок, уже давно признано специалистами. В статье «Из дневника кавказоведа. II. Полевая этнографическая работа на Северном Кавказе» [28] и книге «Записки кавказоведа» [6] Б.А. Калоев описал свои научные экспедиции.

Много сил Б.А. Калоев отдал архивным изысканиям, результатами которых пронизаны все его работы. Ученый впервые ввел в научный оборот большой массив архивных данных. Б.А. Калоев широко опирался в своих научных исследованиях и на вспомогательные данные археологии, языкознания, фольклористики, антропологии, музейные источники.

Не подлежит сомнению, что Б.А. Калоев внес большой вклад в разработку кавказоведческих проблем: этногенеза и этнической истории, историкоэтнографического изучения традиционной и современной культуры, современных этнических и культурно-бытовых процессов. Ученый продолжил лучшие традиции академического кавказоведения, развил их в своих многочисленных кавказоведческих трудах.

\section{БИБЛИОГРАФИЧЕСКИЙ СПИСОК}

1. Калоев Б.А. Осетины. Историко-этнографическое исследование. - М., 2004.

2. Калоев Б.А. Моздокские осетины. Авторефр. дис. ... канд. ист. наук. - М., 1951.

3. Народы Кавказа. Серия «Народы мира. Этнограффические очерки». Т. 1. - М., 1960; T. 2. М., 1962.

4. Народы Кавказа. Серия «Народы мира. Этнографические очерки». Т. 1. - М., 1960.

5. Очерки общей этнографии. Азиатская часть СССР. M., 1960.

6. Калоев Б.А. Записки кавказоведа. - Владикавказ, 2002. 7. Калоев Б.А. Поездка в Чечено-Ингушскую АССР // Cоветская этнографиия. 1958. № 4. С. 128-133.

8. Калоев Б.А. Из истории русско-чеченских экономических и культурных связей // Советская этнография. 1961. № 1. C. 41-53.

9. Калоев Б.А. Чеченцы // Народы Кавказа. Серия «Народы мира. Этнографрические очерки». T. 1. - М., 1960. С. 345374.

10. Калоев Б.А. Ингуши // Народы Кавказа. Серия «Народы мира. Этнографические очерки». Т. 1. - М., 1960. С. 375390

11. Страницы отечественного кавказоведения. - М., 1992.

12. Калоев Б.А. Из истории земельных отношений у агулов в XIX начале XX в. // Краткие сообщения Института этно- графрии АН СССР. 1954. Вып. 20. С. 44-51;

13. Калоев Б.А. Поселения и жилища агулов // Краткие сообщения Института этнографрии АН СССР. 1955. Вып. 23. C. 34-45.

14. Калоев Б.А. Агулы // Народы Дагестана. Сб. статей. M., 1955. C. 204-217.

15. Калоев Б.А. Агулы // Народы Кавказа. Серия «Народы мира. Этнографические очерки». Т. 1. - М., 1960. С. 529536

16. Калоев Б.А. Агулы (историко-этнографический очерк) // Кавказский этнографический сборник. 1962. Вып. 3. С. 69-109.

17. Калоев Б.А. Общественное хозяйство колхоза и производственный быт колхозников // Культура и быт колхозного крестьянства Адыгейской автономной области. М.-Л., 1964. С. $59-82$

18. История народов Северного Кавказа с древнейших времен до кониа XX в. - М., 1988. T. 1.

19. Калоев Б.А. Программа сборов материалов по земледелию скотоводству для Кавказского историко-этнографического атласа. - М., 1968.

20. Калоев Б.А. Земледелие у горских народов Северного Кавказа (некоторые итоги работы над Кавказским историко-этнограффическим атласом) // Советская этнография. 1973. № 3. C. 43-53. 
21. Калоев Б.А. Этнические традиции в земледелии на родов Северного Кавказа // IX Международный конгресс антропологических и этнографических наук. Доклады советской делегации. - М., 1973.

22. Калоев Б.А. Земледелие народов Северного Кавказа. М., 1981.

23. Калоев Б.А. Скотоводство народов Северного Кавказа (с древнейших времен до начала XX века). - М., 1993.

24. Калоев Б.А. Специфика земледелия народов Северного Кавказа и Дагестана // Абдушелишвили М.T., Арутюнов С.А., Калоев Б.А. Народы Кавказа. Антропология, лингвистика, хозяйство. Кн. 3. Материалы к серии «Народы и культуры». - М., 1994.
25. Калоев Б.А. Происхождение некоторых осетино-вайнахских фрамилий (по народным преданиям) // Полевые исследования Института этнографии АН СССР. 1980 - 1981. - M., 1984. C. $214-220$.

26. Калоев Б.А. Осетино-вайнахские этнокультурные связи // Кавказский этнографический сборник. 1989. Вып. IX. C. 137-158.

27. Калоев Б.А. Осетино-балкарские этнографические параллели // Советская этнография. 1972. № 3. С. 20-31.

28. Калоев Б.А. Из дневника кавказоведа. II. Полевая этнографическая работа на Северном Кавказе // Советская этнография. 2000. № 5. С. 156-172.

\section{REFERENCES}

1. Kaloev B.A. Ossetians. Historical and ethnographic research. - M., 2004.

2. Kaloev B.A. Mozdok Ossetians. Author's abstract. dis. ... Cand. ist. sciences. $-M, 1951$

3. Peoples of the Caucasus. Series "Peoples of the World. Ethnographic Essays». T. 1. - M., 1960; T. 2, 1962.

4. Peoples of the Caucasus. Series "Peoples of the World Ethnographic Essays ". T. 1. - M., 1960.

5. Essays on general ethnography. Asian part of the USSR. - M. 1960.

6. Kaloev B.A. Notes of a Caucasian expert. Vladikavkaz, 2002.

7. Kaloev B.A. A trip to the Chechen-Ingush ASSR // Soviet Ethnography. 1958. No. 4. Pp. 128-133.

8. Kaloev B.A. From the history of Russian-Chechen economic and cultural ties // Soviet Ethnography. 1961. No. 1. Pp. 41-53.

9. Kaloev B.A. Chechens // Peoples of the Caucasus. Series "Peoples of the World. Ethnographic Essays». T. 1. - M., 1960 Pp. 345-374.

10. Kaloev B.A. Ingush // Peoples of the Caucasus. Series "Peoples of the World. Ethnographic Essays». T. 1. - M., 1960. Pp. 375-390.

11. Pages of Russian Caucasian Studies.-M., 1992.

12. Kaloev B.A. From the history of land relations among aguls in the nineteenth and early twentieth centuries. // Brief reports of the Institute of Ethnography of the USSR Academy of Sciences, 954. Iss. 20. Pp. 44 - 51;

13. Kaloev B.A. Settlements and dwellings of aguls // Brief reports of the Institute of Ethnography of the USSR Academy of Sciences. 1955. Iss. 23. Pp. 34-45.

14. Kaloev B.A. Aguly // Peoples of Dagestan. Sat. articles. -M. 1955. Pp. 204-217.

15. Kaloev B.A. Aguly // Peoples of the Caucasus. Series «Peoples of the World. Ethnographic Essays». T. 1. - M., 1960. Pp. 529-536.

16. Kaloev B.A. Aguly (historical and ethnographic sketch) Caucasian ethnographic collection, 1962. №. 3. Pp. 69-109.

17. Kaloev B.A. Social economy of the collective farm and the production life of collective farmers // Culture and life of the collective farm peasantry of the Adyghe Autonomous Region. M.-L., 1964. Pp. 59 -82.

18. History of the peoples of the North Caucasus from ancient times to the end of the twentieth century. - M., 1988. Vol. 1.

19. Kaloev B.A. The program of collecting materials on agriculture, cattle breeding for the Caucasian historical and ethnographic atlas. - M., 1968

20. Kaloev B.A. Agriculture among the mountain peoples of the North Caucasus (some results of the work on the Caucasian historical and ethnographic atlas) // Soviet Ethnography, 1973. No. 3. Pp. 43-53.

21. Kaloev B.A. Ethnic traditions in agriculture of the peoples of the North Caucasus // IX International Congress of Anthropological and Ethnographic Sciences. Reports of the Soviet delegation. M., 1973.

22. Kaloev B.A. Agriculture of the peoples of the North Caucasus. M., 1981.

23. Kaloev B.A. Cattle breeding of the peoples of the North Caucasus (from ancient times to the beginning of the 20th century). - M., 1993.

24. Kaloev B.A. Specificity of agriculture of the peoples of the North Caucasus and Dagestan // Abdushelishvili M.T., Arutyunov S.A., Kaloev B.A. Peoples of the Caucasus. Anthropology, linguistics, economy. Book. 3. Materials for the series "Peoples and Cultures». - M., 1994.

25. Kaloev B.A. The origin of some Ossetian-Vainakh surnames (according to folk legends) // Field research of the Institute of Ethnography of the USSR Academy of Sciences. 1980-1981. Moscow, 1984. Pp. 214 - 220.

26. Kaloev B.A. Ossetian-Vainakh ethnocultural ties // Caucasian ethnographic collection, 1989. Issue. IX. Pp. 137-158.

27. Kaloev B.A. Ossetian-Balkarian ethnographic parallels // Soviet ethnography. 1972. No. 3. Pp. 20-31

28. Kaloev B.A. From the diary of a Caucasian scholar. II. Field ethnographic work in the North Caucasus // Soviet ethnography, 2000. No. 5. Pp. 156-172.

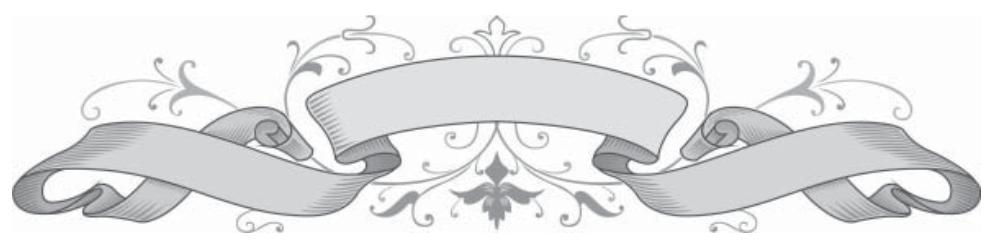

